\title{
The Effects of the Patent Ductus Arteriosus on Diaphragmatic Blood Flow and Function
}

\author{
GAD ALPAN, FRANCOISE MAURAY, AND RONALD I. CLYMAN \\ Cardiovascular Research Institute and Department of Pediatrics, University of California, \\ San Francisco, California 94143
}

\begin{abstract}
Decreased diaphragmatic blood flow $\left(\dot{Q}_{\mathrm{di}}\right)$ is associated with decreased contractility in adult animals. To see whether the decrease in $\dot{Q}_{\mathrm{di}}$ associated with a patent ductus arteriosus was associated with a decrease in diaphragmatic contractility $\left(\mathbf{P}_{\mathrm{di}}\right)$, we prepared 11 near-term fetal lambs by infiltrating the ductus with formalin and placing a snare around it to regulate its patency. The lambs (with open chest) were delivered and mechanically ventilated, and the phrenic nerves and diaphragm were paced (using transvenous wires) at rates of $20 / \mathrm{min}, 60 / \mathrm{min}$, and $100 / \mathrm{min}$ (Inspiratory time/total respiratory cycle time $=$ 0.5 ) for 7 -min contraction periods after 30 -min recovery periods. $\dot{Q}_{\mathrm{di}}$ was measured with radiolabeled microspheres at the end of each contraction period. Diaphragmatic performance was determined by comparing $\mathrm{P}_{\mathrm{di}}$ at the start ( $P_{\mathrm{di}}$-start) and end $\left(\mathbf{P}_{\mathrm{di}}\right.$-end) of the contraction period. When the ductus was closed, $\dot{\mathrm{Q}}_{\mathrm{di}}$ increased 6.9-fold at 20/ min and 9.8 -fold at $100 / \mathrm{min}$ (compared with $\dot{\mathrm{Q}}_{\mathrm{di}}$ at rest). $\mathbf{P}_{\mathrm{di}}$-end was less than $\mathbf{P}_{\mathrm{di}}$-start at all contraction rates, but the reduction was significantly greater at $100 / \mathrm{min}\left(\mathrm{P}_{\mathrm{di}}\right.$-end/ $P_{\mathrm{di}}$-start: $0.80 \pm 0.10$ at $20 / \mathrm{min} ; 0.67 \pm 0.17$ at $100 / \mathrm{min}$ ). $P_{\mathrm{di}}$-start also decreased with increasing rates of contraction. When the ductus was open, the left-to-right shunt was $64 \pm 11 \%$ of left ventricular output. $\dot{Q}_{\mathrm{di}}$ in the unpaced diaphragm was significantly reduced (open $4.0 \pm 3.8$ versus closed, $7.4 \pm 2.4 \mathrm{~mL} / \mathrm{min} / 100 \mathrm{~g}$ ). However, with pacing, $\dot{\mathrm{Q}}_{\mathrm{di}}$ increased with open ductus and so did not differ from $\hat{Q}_{\mathrm{di}}$ with closed ductus. Similarly, at each contraction rate, ductus patency did not alter diaphragmatic performance ( $\mathrm{P}_{\mathrm{di}}$-end $/ \mathrm{P}_{\mathrm{di}}$-start, open versus closed: $20 / \mathrm{min}=0.80 \pm 0.15$ versus $0.80 \pm 0.10 ; 60 / \mathrm{min}=0.76 \pm 0.11$ versus $0.73 \pm$ $0.17 ; 100 / \mathrm{min}=0.62 \pm 0.14$ versus $0.67 \pm 0.17)$. We conclude that diaphragm performance decreases at faster contraction rates despite an increase in $\dot{\mathrm{Q}}_{\mathrm{di}}$. Although a patent ductus arteriosus reduces $\dot{\mathrm{Q}}_{\mathrm{di}}$ in the noncontracting diaphragm, during contractions $\dot{Q}_{\mathrm{di}}$ can increase to levels achieved when the ductus is closed so that there is no change in diaphragmatic performance. (Pediatr Res 28: 437-445, 1990)
\end{abstract}

\section{Abbreviations}

$\mathbf{P}_{\mathrm{di}}$, diaphragmatic contractility

$\mathbf{P}_{\mathrm{di}}$-start, contractile force at start of diaphragmatic pacing $P_{\mathrm{di}}$-end, contractile force at end of diaphragmatic pacing $\mathrm{FiO}_{2}$, fractional inspired oxygen

CPAP, continuous positive airway pressure

EMG, electromyograph

Received March 28, 1990; June 8, 1990

Correspondence and reprint requests: Ronald I. Clyman, M.D., Box 0544 HSE 1403, University of California, San Franscisco, San Francisco, CA 94143

Supported by Pulmonary Special Center of Research Grant HL 27356 from the United States Public Health Service. G.A. was supported by an American Heart Institute, California Affiliate, Fellowship with funds contributed by the San Mateo County chapter.
$\mathbf{P}_{\text {ga }}$, gastric pressure

Diaphragmatic muscle fatigue, the inability to generate or sustain contractile force, is an important feature of respiratory failure (1). Diaphragmatic fatigue has been recorded when general metabolic demands have been extreme, as well as under severe respiratory loading (2-4). The exact mechanism that causes fatigue is unknown. Normotensive, spontaneously breathing, adult animals are able to increase their diaphragmatic blood flow to meet increased energy demands $(2,3,5)$. However, a number of experimental conditions have been described in which decreased diaphragmatic blood flow is related to diaphragmatic fatigue (6-8). When subjected to hypotensive shock, either cardiogenic (9) or hemorrhagic (10), experimental animals exhibit diaphragmatic fatigue, which is related to reduced energy supply. Recently, work on skeletal muscle fatigue has suggested that decreased blood flow may cause fatigue by mechanisms independent of oxygen and substrate delivery (11).

A patent ductus arteriosus is a vascular communication between the systemic and pulmonary vascular beds. It is present in full-term newborn lambs and humans in the first hours after delivery and frequently persists for several days in the premature neonate. Patency of the ductus arteriosus is thought to aggravate respiratory distress in premature infants in the first few days of life. Although patency of the ductus arteriosus has been assumed to cause pulmonary edema, we have recently demonstrated that, in premature lambs, a patent ductus arteriosus does not cause increased water accumulation or net protein transudation into the lungs in the early hours after delivery (12). Thus, we considered the possibility that the adverse effects of ductus patency in premature infants could be mediated by its possible effects on diaphragmatic blood flow and function. Patency of the ductus arteriosus is associated with a left-to-right extracardiac shunt with a "run-off" of aortic blood flow to the pulmonary circulation. Consequently, there is a reduction in systemic blood pressure and reduced perfusion to splanchnic organs and skeletal muscles (13). We have previously observed that paralyzed, mechanically ventilated newborn lambs with a patent ductus arteriosus have a significant $(40 \%)$ reduction in diaphragmatic blood flow (13). Therefore, we hypothesized that reduced diaphragmatic blood flow, apparent at rest in lambs with a patent ductus arteriosus, would be even more compromised during periods of increased metabolic demand, when the diaphragm would require increased blood flow.

We therefore asked the following questions: 1 ) Is patency of the ductus arteriosus associated with diaphragmatic fatigue at lesser metabolic demands than when the ductus is closed?; 2) Does diaphragmatic fatigue correspond to a reduction in diaphragmatic blood flow? We chose to pace the diaphragm at increasing rates of contraction because this is a major determinant of diaphragmatic blood flow (7). Because the costal and 
crural portions of the diaphragm have different embryonic origin, derive their innervation from different parts of the cervical spinal tract, and have different mechanical actions during inspiration (14), we measured blood supply to these parts individually. We reasoned that different requirements may be reflected in disparate measures of blood flow with increasing demands. We also attempted to measure indices of oxygen metabolism in the diaphragm so as to note possible compensatory mechanisms that may be brought into play when metabolic demands are increased.

\section{MATERIALS AND METHODS}

Surgical preparation. Surgery was performed on time-dated pregnant Western mixed-breed ewes at 139-143 d gestation (term, $145 \mathrm{~d}$ ). A continuous infusion of $0.9 \% \mathrm{NaCl}$ was given to the ewe throughout surgery. Epidural anesthesia was induced with $4 \mathrm{~mL}$ of $1 \%$ tetracaine hydrochloride; ketamine $(100 \mathrm{mg})$ was administered i.v. for sedation as required. Local anesthesia with $0.5 \%$ lidocaine hydrochloride was used for all maternal and fetal incisions. Using this combination of ketamine and local anesthesia, fetuses did not respond to surgical incisions. In addition, the fetuses and newborn lambs were anesthetized throughout the experiment with repeated small boluses of pentobarbital sodium in doses just sufficient to depress the corneal reflex.

Polyvinyl catheters were inserted into the ewe's pedal vein and artery and advanced into the inferior vena cava and descending aorta, respectively. Through a midline incision, a hysterotomy was performed and polyvinyl catheters were similarly inserted into the fetal pedal vein and artery; these were advanced to the fetal inferior vena cava and descending aorta, respectively. The fetal left chest was then identified and a left thoracotomy performed through the 5th intercostal space; the left lung was retracted to expose the great vessels and the ductus arteriosus. After the ductus was dissected from the surrounding tissue, $10 \%$ buffered formalin solution was injected into the vessel wall to destroy the muscular layer. A mechanical snare (made from a cardiac catheterization guide wire and a catheter sheath) was then looped around the ductus and brought out through the fetal chest wall. A catheter was placed in the fetal pulmonary artery, and the left thoracotomy was closed.

Bilateral thoracotomies were made through the fetal 8th intercostal spaces. Through the right thoracotomy, a polyvinyl catheter was inserted into the right diaphragmatic phrenic vein under direct visualization and secured in position by sutures. Through the left thoracotomy, a three-pronged fish-hook electrode, insulated up to $5 \mathrm{~mm}$ from the tips, was attached to the left anterior costal diaphragm. The raw EMG signal was passed through a 9852A EMG averaging coupler (Sensormedics, Anaheim, CA); the coupler acted as a voltage amplitude filter and had a band width of $5.3 \mathrm{~Hz}$ to $1000 \mathrm{~Hz}$. The two lateral thoracotomies were left open throughout the experiment to eliminate the effects of pleural pressure, as well as chest wall and lung expansion, on diaphragmatic geometry (15).

The fetus was then delivered onto the maternal abdomen. A tracheotomy was performed and the fetal trachea intubated with a $4.5 \mathrm{~F}$ cuffed endotracheal tube. The umbilical cord was then ligated and the lamb delivered to a warming table, where mechanical ventilation was initiated with a time-cycled, constantflow infant ventilator (Sechrist, Anaheim, CA). Under local anesthesia, additional polyvinyl catheters were inserted into the right upper pedal and umbilical arteries and into the carotid artery; the latter catheter was advanced into the left ventricle.

Figure 1 shows a schematic representation of the experimental set-up. The lamb's lower abdomen and lower chest were snugly wrapped with an ace bandage to increase the work load on the diaphragm. Once tightened, the ace bandage was left undisturbed throughout the experiment. Our index of the force generated by diaphragmatic contraction, $\mathrm{P}_{\mathrm{di}}$, was measured with a thin-walled latex balloon ( $4 \mathrm{~cm}$ long) placed between the abdominal wall and the ace bandage. The balloon was connected via a polyeth-

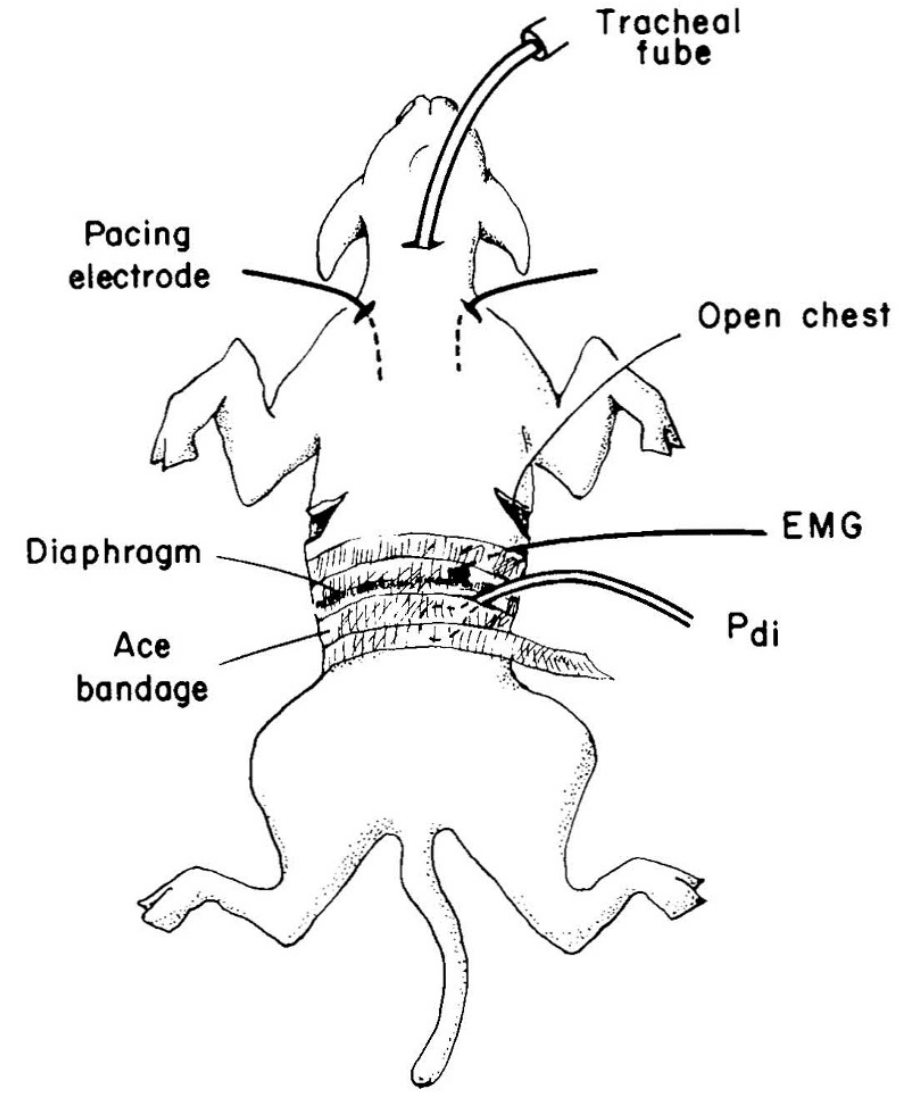

Fig. 1. Schematic representation of experimental set-up. The lamb's lower abdomen and lower chest were wrapped with an ace bandage to increase diaphragmatic work load. A latex balloon between the abdominal wall and the ace bandage was used to measure $P_{\mathrm{di}}$. An electrode was attached to the left anterior costal diaphragm to record EMG. Bipolar electrodes were placed into the jugular veins to stimulate the phrenic nerves.

ylene catheter to a differential pressure transducer (MP-45-28, Validyne, Northridge, CA), one port open to atmospheric pressure. Measurements were made with the balloon containing 0.5 $\mathrm{mL}$ air. The balloon was calibrated before each experiment; its response characteristics were stable between balloon volumes of 0.4 and $0.65 \mathrm{~mL}$. The balloon was deflated between experimental measurements; it was inflated $20 \mathrm{~s}$ before each measurement.

The phrenic nerves were stimulated transvenously by bipolar electrodes inserted into both jugular veins. The electrode tips were positioned by initiating electrical signals from a stimulator and signal programmer stimulator 6002 and train programmer 6091, Palmer Bioscience, Kent, England) and advancing both electrodes until the diaphragm contracted maximally when stimulated with 5-7.5 V. Once positioned, the pacing electrodes were sutured tightly in place. The stimulator voltage then was increased incrementally until no further increase in $\mathrm{P}_{\mathrm{di}}$ was observed; this was called the "maximal pacing voltage." After the maximal pacing voltage was reached, the voltage was increased by a further $20 \%$ to ensure "supramaximal" stimulation. In this study, supramaximal voltages were $12 \pm 2 \mathrm{~V}$ (mean $\pm \mathrm{SD}$ ).

In Table 1 , we compared our measure of $\mathrm{P}_{\mathrm{di}}$ with measurements made with a balloon-tipped catheter placed in the stomach via the esophagus $\left(\mathrm{P}_{\mathrm{ga}}\right)$; there was no significant difference between the two techniques in detecting the changes in pressure when the stimulator voltage was incrementally increased. In two animals, we measured both $\mathrm{P}_{\mathrm{ga}}$ and $\mathrm{P}_{\mathrm{di}}$ simultaneously; in each lamb, the stimulator voltage was increased incrementally from 0 to $100 \%$ of the maximal pacing voltage. The relationship between $\mathrm{P}_{\mathrm{di}}$ and $\mathrm{P}_{\mathrm{ga}}$ (expressed as a percent of the $\mathrm{P}_{\mathrm{di}}$-maximal and $\mathrm{P}_{\mathrm{ga}}-$ maximal; see footnote, Table 1 , for definitions) was $\mathrm{P}_{\mathrm{di}}=(1.03$ 
Table 1. Comparison of $P_{d i}$ with $P_{g a}$ at different pacing voltages*

\begin{tabular}{lccccccc}
\hline & \multicolumn{7}{c}{$\%$ of maximal pacing voltage } \\
\cline { 2 - 8 } & 40 & 50 & 70 & 80 & 90 & $100 \dagger$ & 120 \\
\hline $\mathrm{P}_{\text {ga }} \ddagger$ & $25 \pm 5$ & & $78 \pm 3$ & $83 \pm 0$ & & 100 & $100 \pm 0$ \\
$n$ & 2 & & 3 & 3 & & 4 & 4 \\
& & & & & & & \\
$\mathrm{P}_{\text {di }} \neq$ & $24 \pm 9$ & $49 \pm 12$ & $77 \pm 10$ & $84 \pm 9$ & $93 \pm 0$ & 100 & $100 \pm 0$ \\
$n$ & 4 & 6 & 11 & 5 & 4 & 11 & 11 \\
\hline
\end{tabular}

* Pacing electrodes were placed as described in Materials and Methods. The force generated by diaphragmatic contraction was measured by the change in $\mathrm{P}_{\mathrm{ga}}$ in four lambs, and $\mathrm{P}_{\mathrm{di}}$ (abdominal wall pressure) in 11 lambs. Contractions were measured in all lambs when the ductus was open. Contractions were induced by a train of $0.2-\mathrm{ms}$ pulses at $50 \mathrm{~Hz}$, which were maintained for $1.5 \mathrm{~s}$. The stimulator voltage was increased incrementally until no further increase in $\mathrm{P}_{\mathrm{di}}$ or $\mathrm{P}_{\mathrm{ga}}$ was observed; this was called the "maximal pacing voltage."

† The maximal pacing voltage is normalized to 100 in each animal and different stimulating voltages are expressed as the $\%$ of maximal voltage. The maximal pacing voltage was $10 \pm 2 \mathrm{~V}$ (mean $\pm \mathrm{SD}$ ) in the four lambs with $P_{g a}$ measurements and $10 \pm 2 \mathrm{~V}$ in the 11 lambs with $\mathrm{P}_{\mathrm{di}}$ measurements. $\mathrm{P}_{\mathrm{ga}}$-maximal and $\mathrm{P}_{\mathrm{di}}$-maximal were the pressure changes measured at maximal pacing voltage: $\mathrm{P}_{\mathrm{ga}}$-maximal $=5.5 \pm 2.7$ $\mathrm{cm} \mathrm{H}_{2} \mathrm{O}(n=4)$, and $\mathrm{P}_{\mathrm{di}}$-maximal $=6.8 \pm 1.9 \mathrm{~cm} \mathrm{H}_{2} \mathrm{O}(n=11)(p=$ NS).

† The values of $\mathrm{P}_{\mathrm{ga}}$ and $\mathrm{P}_{\mathrm{di}}$ are expressed as a $\%$ of the $\mathrm{P}_{\mathrm{ga}}$-maximal and $\mathrm{P}_{\mathrm{d} i}$-maximal in each lamb. $n=$ number of lambs with pressure measurements at the indicated pacing voltage.

$\left.\times \mathrm{P}_{\mathrm{ga}}\right)-1.3$, mean $\mathrm{P}_{\mathrm{ga}}=61 \pm 41, r=0.99, n=9$. However, during prolonged (7-min) pacing periods, we found considerable variability in the peak pressure measurements recorded by $\mathrm{P}_{\mathrm{ga}}$, whereas the coefficient of variation for our measure of $P_{d i}$ was less than $5 \%$. Because the purpose of our study was to compare diaphragmatic force during different states of ductus patency, we used our measure of $\mathrm{P}_{\mathrm{di}}$ because it had less variability than the measurements recorded by $\mathrm{P}_{\mathrm{ga}}$.

All intravascular catheters were kept patent during the experiment by infusion of small boluses of heparinized $5 \%$ dextrose in water $(<1 \mathrm{~mL} / \mathrm{kg} / \mathrm{h})$. The lambs received an infusion of $5 \%$ dextrose with $\mathrm{NaHCO}_{3}$ at a rate of $10 \mathrm{~mL} / \mathrm{kg} / \mathrm{h}(2 \mathrm{mEq} / \mathrm{kg} / \mathrm{h}, 2$ $\mathrm{mmol} / \mathrm{kg} / \mathrm{h}$ ). The lambs were dried with a towel and covered with a plastic sheet to reduce evaporative heat loss. Rectal temperature was maintained at $38-39^{\circ} \mathrm{C}$ with an Aquamatic Kpad (American Hospital Supply, McGaw Park, IL) and radiant heat lamps. Heparinized fetal or maternal blood was transfused to replace blood loss from sampling.

Experimental protocol. The experiment began when the umbilical cord was ligated. The ventilator settings were set at a peak inspiratory pressure of $25 \mathrm{~cm} \mathrm{H}_{2} \mathrm{O}$, a positive end-expiratory pressure of $2.5-3 \mathrm{~cm} \mathrm{H} \mathrm{H}_{2} \mathrm{O}$, inspiratory time of $0.6 \mathrm{~s}$, respiratory rate of $40-50$ breaths/min, and $\mathrm{FiO}_{2}$ of 1.0 . Peak inspiratory pressures were then changed to maintain arterial $\mathrm{PCO}_{2}$ values in the range of $30-35 \mathrm{~mm} \mathrm{Hg}(4.0-4.7 \mathrm{kPa}) \mathrm{FiO}_{2}$ was reduced to maintain arterial $\mathrm{PO}_{2}$ values in the range of $100-120 \mathrm{~mm} \mathrm{Hg}$ $(13.3-16 \mathrm{kPa})$. The settings at which these values were attained were: peak inspiratory pressures of $23.5 \pm 3.0 \mathrm{~cm} \mathrm{H} \mathrm{H}_{2} \mathrm{O}$ and $\mathrm{FiO}_{2}$ of $0.51 \pm 0.18$ (mean $\pm \mathrm{SD}$ ). The animals were allowed to stabilize for $2.5 \mathrm{~h}$ after delivery before any studies were begun.

Two groups of animals were studied. In the first group of animals $(n=5$; weight $=4.04 \pm 1.14 \mathrm{~kg}$, gestational age $=141$ \pm 0.5 ), we studied the effects of the experimental time course on diaphragmatic function. In this group of animals the ductus was closed shortly after delivery (by tightening the snare). The diaphragm was studied when paced at the following sequence of contraction rates: 1) $60 / \mathrm{min}$, 2) $100 / \mathrm{min}$, 3) $20 / \mathrm{min}$, and 4) at rest (no pacing). Each contraction was induced by a train of 0.2 ms pulses at $50 \mathrm{~Hz}$. Peak tetanic tensions were achieved within
$250 \mathrm{~ms}$. For contraction rates of 20,60 , and $100 / \mathrm{min}$, these repetitive pulse trains were maintained for $1.5,0.5$, and $0.3 \mathrm{~s}$, respectively, with $1.5,0.5$, and 0.3 s quiescent periods per contraction, respectively. Because both frequency of contraction and duty cycle are important determinants of diaphragmatic blood flow (7), we kept the duty cycle constant (at a value of 0.5 ) so that the total contraction time per min was the same at the various rates of contraction.

Each period of pacing was maintained for $7 \mathrm{~min}$, and $30 \mathrm{~min}$ were allowed for recovery between pacing periods at the different contraction rates. During each 7-min pacing period, a number of measurements were made. Mechanical ventilation was discontinued upon initiation of pacing, and the lungs were distended with a CPAP of $3.0 \mathrm{~cm} \mathrm{H}_{2} \mathrm{O}$. CPAP was maintained for $20 \mathrm{~s}$, during which time pressure tracings from the abdominal wall latex balloon were recorded. The mean amplitude of the last three consecutive waves of this $20-\mathrm{s}$ interval was recorded as $\mathrm{P}_{\mathrm{d}}$ start.

After measurement of $\mathrm{P}_{\mathrm{di}}$-start, mechanical ventilation was restarted; the lambs were ventilated throughout the rest of the 7min pacing period while the diaphragm received the same rate of pacing. Arterial and phrenic venous blood gases and lactate concentrations were measured from blood samples drawn 1.5 min after pacing was begun. Blood flow was measured 5 min after pacing was begun using one of nine different radiolabeled microspheres $(15 \mu)(16)$; over a 90 -s interval, the radionuclidelabeled microsphere was injected into the left ventricle as reference blood samples were withdrawn simultaneously from the right brachial and carotid arteries (13). This group of measurements was made during each contraction rate $(60,100$, and $20 /$ $\min )$.

After the initial series of contraction rates (period I, Fig. 3), the diaphragm was paced again at the same contraction rates in the same sequence $(60,100$, and $20 / \mathrm{min}$; period II, Fig. 3$)$.

Figure 2 shows the values of $\mathrm{P}_{\mathrm{di}}$-start at the various rates of contraction. As previously demonstrated (17), $\mathrm{P}_{\mathrm{di}}$-start was lower at contraction rates of $100 / \mathrm{min}$ than at $20 / \mathrm{min}$ (mean reduction of $13-17 \%$ ). At any contraction rate, $\mathrm{P}_{\mathrm{di}}$-start during the first sequence of pacing (period I) did not differ from $\mathrm{P}_{\mathrm{di}}$-start during the second sequence (period II). We concluded that $\mathrm{P}_{\mathrm{di}}$-start was a stable measure during the time course of this experiment. In addition, the near identity of $\mathrm{P}_{\mathrm{di}}$-start for periods I and II, at each rate of contraction, suggested that the sequence of pacing did not significantly affect $\mathrm{P}_{\mathrm{di}}$ values.

The second group of animals formed the core of our study. This group included 11 lambs; mean weight was $3.86 \pm 0.81 \mathrm{~kg}$,

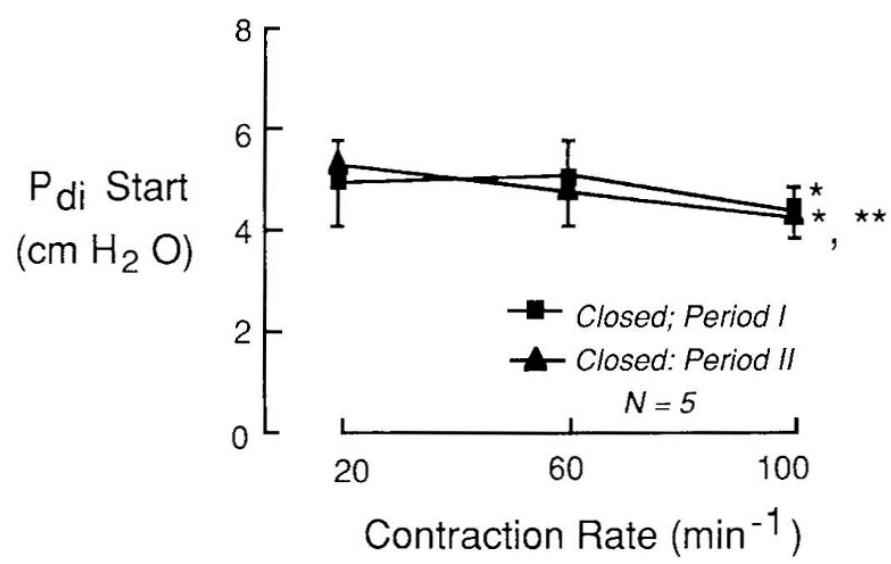

Fig. 2. $P_{\mathrm{di}}$-start for group 1 lambs. The ductus was closed shortly after delivery. Pacing sequence of 60,100 , and $20 / \mathrm{min}($ period $I)$ was repeated (period $I I) .{ }^{*}$ Compared with contractions of $20 / \mathrm{min}, p<0.04$. ${ }^{* *} \mathrm{Com}$ pared with contractions of $60 / \mathrm{min}, p<0.01$. Values represent mean \pm SD. 
and mean gestational age was $141 \pm 1 \mathrm{~d}$ (mean $\pm \mathrm{SD}$ ). After a 2.5-h stabilization period, diaphragmatic function was studied with the ductus arteriosus initially patent. The diaphragm was paced in the same sequence of contraction rates as in the first group of animals. As before, each pacing period was maintained for $7 \mathrm{~min}$, and $30 \mathrm{~min}$ were allowed for recovery between periods of contraction.

During each pacing period, the lungs were distended initially with CPAP of $3.0 \mathrm{~cm} \mathrm{H}_{2} \mathrm{O}$. CPAP was maintained for $20 \mathrm{~s}$ while pressure tracings from the latex balloon were recorded. As before, the mean amplitude of the last three consecutive waves was recorded as $\mathrm{P}_{\mathrm{di}}$-start. In addition, CPAP was applied during the last $20 \mathrm{~s}$ of each pacing period, the mean amplitude of the last three consecutive waves being recorded at $\mathrm{P}_{\mathrm{di}}$-end. Otherwise, the lambs were mechanically ventilated throughout the 7-min study period. Blood gases, assays of lactate, and microsphere flow studies were carried out as for the first group of animals.

In the second group of animals, after the initial sequence of diaphragmatic pacings (with the ductus patent), the ductus arteriosus was closed by tightening the mechanical snare. The diaphragm was then studied in the same sequence as before; pacing at contraction rates of 60,100 , and $20 / \mathrm{min}$ and at rest. As before, each rate of contraction was maintained for $7 \mathrm{~min}$, measurements performed as above, and $30 \mathrm{~min}$ allowed for recovery between each pacing period.

Throughout the experiment, vascular and left ventricular pressures were measured continuously with a Sensormedics Dynograph multichannel recorder and Beckman pressure transducers (Sensormedics). Signals were averaged electronically to obtain mean pressures. The differential pressure transducer used to measure $P_{\mathrm{di}}$ and the EMG electrode were connected to the same multichannel recorder. The EMG signal was rectified and filtered through an EMG averaging coupler (Sensormedics).

At the end of the experiment, the animals were killed with 4 $\mathrm{mL}$ of euthanasia solution (Anthony Products Co., Arcadia, CA). When dissected, ductal closure was confirmed as were the positions of the diaphragmatic venous catheter and other catheters.

Diaphragmatic function and pacing. $\mathrm{P}_{\mathrm{di}}$-start was our measure of diaphragmatic contractile force. The ratio of $\mathrm{P}_{\mathrm{di}}$-end $/ \mathrm{P}_{\mathrm{di}}$-start was our measure of the diaphragm's ability to sustain contractile force.

The EMG electrode provided a measure of compound diaphragmatic action potential. This was a measure of the integrity and stability of the transmission path from the stimulator output, via pacing electrodes, to the EMG electrode output. Peak diaphragmatic EMG signal output did not change once the supramaximal pacing voltage had been set; therefore, any changes in $\mathrm{P}_{\mathrm{di}}$ could legitimately be attributed to changes in diaphragmatic mechanical performance, rather than to other factors such as change in stimulator output, unstable electrode positioning, or increased impedance due to thrombus formation.

Cardiovascular function measurements. At the end of the experiment, the organs and carcass were separated, placed in formalin, incinerated at $325^{\circ} \mathrm{C}$ for $72 \mathrm{~h}$, pulverized, and placed in counting vials. The diaphragm, in particular, was excised from its attachment to the chest wall, the central tendon was dissected, and the muscular diaphragm divided into its costal and crural parts. A muscular specimen overlying the mid-left scapula was also dissected separately to provide a measure of noncontracting skeletal muscle flow. This tissue was referred to as "scapula muscle." The amount of radionuclide in each organ and reference blood sample was measured with a well-type gamma scintillation counter and multiple-channel pulse height analyzer (13). Left ventricular output, pulmonary blood flow, and blood flow through the ductus arteriosus were calculated from the concentration of microspheres in the reference samples, the total number of microspheres recovered from the whole animal, and the total number of microspheres in the lungs (13). Bronchial blood flow was assumed to be $8 \%$ of left ventricular output; this assumption was based on measurements made in 35 premature newborn lambs with ligated ductus (Clyman RI, unpublished observations). Pulmonary blood flow, therefore, was considered equal to the left ventricular output minus the estimated bronchial blood flow (13).

Chemical analysis. Arterial and venous $\mathrm{pH}, \mathrm{PCO}_{2}$, and $\mathrm{PO}_{2}$ were measured using a blood gas analyzer (Corning Medical \& Scientific, Medfield, MA). Hb concentration and oxygen saturation were measured with an OSM2 Hemoximeter (Radiometer, Copenhagen, Denmark). Arterial and venous whole blood lactate concentrations were measured electroenzymatically (23L lactate analyzer, Yellow Springs Instruments Co., Yellow Springs, $\mathrm{OH}$ ) Samples for lactate measurements were kept on ice and measured within 3 min of blood withdrawal.

Calculations. Because $\mathrm{PO}_{2}$ measurements were not always available from the phrenic venous samples, arterial and venous oxygen content $(\mathrm{mL} \mathrm{O} / 100 \mathrm{~mL})$ was estimated from: $[\mathrm{Hb}] \times$ $1.34 \times \% \mathrm{O}_{2}$ - saturation, where $[\mathrm{Hb}]=\mathrm{H}$ concentration $(\mathrm{g} / 100$ $\mathrm{mL})$. Oxygen delivery to the diaphragm $\left(\mathrm{DO}_{2}\right)$ was calculated from: $\dot{D O}_{2}=\mathrm{CaO}_{2} \times \dot{\mathrm{Q}}_{\mathrm{di}}$, where $\mathrm{CaO}_{2}=$ oxygen content of descending aortic blood and $\dot{\mathrm{Q}}_{\mathrm{di}}=$ diaphragmatic blood flow Oxygen consumption $\left(\dot{\mathrm{VO}}_{2}\right)$ was calculated from: $\dot{\mathrm{VO}}_{2}=\left(\mathrm{CaO}_{2}\right.$ - $\left.\mathrm{CvO}_{2}\right) \times \dot{\mathrm{Q}}_{\mathrm{di}}$, where $\mathrm{CaO}_{2}$ and $\mathrm{CvO}_{2}$ are arterial and phrenic venous oxygen contents, respectively. The net lactate efflux from the diaphragm $\left(\dot{\mathrm{Q}}_{\mathrm{lac}}\right)$ was calculated from: $\dot{\mathrm{Q}}_{\mathrm{lac}}=$ (venous lactate concentration - arterial lactate concentration $) \times \dot{Q}_{\text {di }}$. Diaphragmatic vascular resistance (DVR) was calculated from: DVR = $\left(\overline{\mathrm{P}}_{\mathrm{fa}}-\overline{\mathrm{P}}_{\mathrm{IVC}}\right) / \dot{\mathrm{Q}}_{\mathrm{di}}$, where $\overline{\mathrm{P}}_{\mathrm{fa}}=$ mean femoral artery pressure, and $\overline{\mathrm{P}}_{\mathrm{IVC}}=$ mean pressure in the inferior vena cava.

Statistics. The comparisons to be made were predetermined before we began this study. The effect of ductal patency on diaphragmatic and cardiovascular measurements at the different rates of contraction was tested by two-factor (ductus patency and contraction rate) analysis of variance with replication. When analysis of variance revealed significant differences, we used the Scheffe's test for a posteriori comparisons. Values of $p<0.05$ were considered statistically significant. All values are presented as mean $\pm \mathrm{SD}$.

\section{RESULTS}

Table 2 shows the effects of different rates of diaphragm contraction on the left ventricular output, pulmonary blood flow, and pressures in the pulmonary and femoral arteries and left ventricle at end-diastole when the ductus arteriosus was open or closed. Because none of the hemodynamic variables were altered by changes in the rate of diaphragm contraction, the values at rest and at the different contraction rates were pooled to give mean results. When the ductus was open, left ventricular output, pulmonary blood flow, mean pulmonary artery pressure, and left ventricular end-diastolic pressure were significantly higher, whereas mean femoral artery pressure was significantly lower than when the ductus was closed. These findings, which have been observed previously (13), are consistent with the amount of left-to-right shunt through the ductus arteriosus $(64 \%$ of left ventricular output) (13).

With increasing rates of diaphragm contraction (Fig. 3), there were progressive decreases both in $\mathrm{P}_{\mathrm{di}}$-start, our index of diaphragmatic contractile force, and in $\mathrm{P}_{\mathrm{di}}$-end $/ \mathrm{P}_{\mathrm{di}}$-start, our index of the diaphragm's ability to sustain contractile force. Neither of these indices of diaphragmatic function was changed by studying the lambs with the ductus open or closed at any contraction rate.

As we have observed previously (13), when the diaphragm was at rest, blood flow to the diaphragm (as well as to the scapula, carcass, gut, and kidneys) was significantly reduced $(p<0.05)$ when the ductus was open compared with when it was closed (Table 3). However, with diaphragmatic contraction, diaphragmatic vascular resistance decreased precipitously (Table 4), so that diaphragmatic blood flow increased both when the ductus was open and when it was closed. As a result, at any given contraction rate, blood flow to the diaphragm did not differ 
Table 2. Hemodynamic data in fetal lambs with open and closed ductus when diaphragm was at rest and at different rates of contraction $(n=11)^{*}$

\begin{tabular}{|c|c|c|c|c|c|}
\hline & Rest & $20 / \mathrm{min}$ & $60 / \mathrm{min}$ & $100 / \mathrm{min}$ & Mean \\
\hline \multicolumn{6}{|l|}{ Open ductus } \\
\hline $\mathrm{LVO}(\mathrm{mL} / \mathrm{min} / \mathrm{kg})$ & $315 \pm 96$ & $333 \pm 114$ & $348 \pm 93$ & $337 \pm 157$ & $333 \pm 114 \dagger$ \\
\hline$\dot{\mathrm{Q} p}(\mathrm{~mL} / \mathrm{min} / \mathrm{kg})$ & $289 \pm 89$ & $306 \pm 105$ & $320 \pm 86$ & $315 \pm 116$ & $307 \pm 105 \dagger$ \\
\hline PDA shunt (\% LVO) & $59 \pm 13$ & $64 \pm 12$ & $67 \pm 8$ & $65 \pm 12$ & $64 \pm 11 \dagger$ \\
\hline \multicolumn{6}{|l|}{$\overline{\mathrm{P}}_{\mathrm{pa}}$} \\
\hline$(\mathrm{mm} \mathrm{Hg})$ & $44 \pm 6$ & $43 \pm 7$ & $45 \pm 5$ & $43 \pm 6$ & $44 \pm 6 \dagger$ \\
\hline$(\mathrm{kPa})$ & $5.9 \pm 0.8$ & $5.7 \pm 0.9$ & $6.0 \pm 0.7$ & $5.7 \pm 0.8$ & $5.9 \pm 0.8$ \\
\hline \multicolumn{6}{|l|}{$\overline{\mathrm{P}}_{\mathrm{fa}}$} \\
\hline$(\mathrm{mm} \mathrm{Hg})$ & $48 \pm 7$ & $48 \pm 8$ & $50 \pm 6$ & $48 \pm 8$ & $49 \pm 7 \ddagger$ \\
\hline$(\mathrm{kPa})$ & $6.4 \pm 0.9$ & $6.4 \pm 11$ & $6.7 \pm 0.8$ & $6.4 \pm 1.1$ & $6.5 \pm 0.9$ \\
\hline \multicolumn{6}{|l|}{$P_{\text {LVED }}$} \\
\hline$(\mathrm{mm} \mathrm{Hg})$ & $10 \pm 4$ & $10 \pm 4$ & $12 \pm 6$ & $11 \pm 4$ & $11 \pm 4 \dagger$ \\
\hline$(\mathrm{kPa})$ & $1.3 \pm 0.5$ & $1.3 \pm 0.5$ & $1.6 \pm 0.8$ & $1.5 \pm 0.5$ & $1.5 \pm 0.5$ \\
\hline \multicolumn{6}{|l|}{ Closed ductus } \\
\hline $\mathrm{LVO}(\mathrm{mL} / \mathrm{min} / \mathrm{kg})$ & $141 \pm 37$ & $151 \pm 42$ & $139 \pm 45$ & $140 \pm 35$ & $143 \pm 39$ \\
\hline $\mathrm{Q} \mathrm{p}(\mathrm{mL} / \mathrm{min} / \mathrm{kg})$ & $130 \pm 34$ & $139 \pm 39$ & $127 \pm 41$ & $128 \pm 32$ & $132 \pm 36$ \\
\hline PDA shunt (\% LVO) & $13 \pm 10$ & $14 \pm 11$ & $15 \pm 12$ & $15 \pm 13$ & $15 \pm 11$ \\
\hline \multicolumn{6}{|l|}{$\overline{\mathrm{P}}_{\mathrm{pa}}$} \\
\hline$(\mathrm{mm} \mathrm{Hg})$ & $31 \pm 5$ & $30 \pm 4$ & $30 \pm 4$ & $30 \pm 4$ & $31 \pm 4$ \\
\hline$(\mathrm{kPa})$ & $4.1 \pm 0.7$ & $4.0 \pm 0.5$ & $4.0 \pm 0.5$ & $4.0 \pm 0.5$ & $4.1 \pm 0.5$ \\
\hline \multicolumn{6}{|l|}{$\overline{\mathrm{P}}_{\mathrm{fa}}$} \\
\hline$(\mathrm{mm} \mathrm{Hg})$ & $55 \pm 12$ & $54 \pm 11$ & $56 \pm 11$ & $55 \pm 12$ & $55 \pm 11$ \\
\hline$(\mathrm{kPa})$ & $7.3 \pm 1.6$ & $7.2 \pm 1.5$ & $7.4 \pm 1.5$ & $7.3 \pm 1.6$ & $7.3 \pm 1.5$ \\
\hline \multicolumn{6}{|l|}{$P_{\text {LVED }}$} \\
\hline$(\mathrm{mm} \mathrm{Hg})$ & $6 \pm 3$ & $6 \pm 3$ & $6 \pm 3$ & $6 \pm 4$ & $6 \pm 3$ \\
\hline$(\mathrm{kPa})$ & $0.8 \pm 0.4$ & $0.8 \pm 0.4$ & $0.8 \pm 0.4$ & $0.8 \pm 0.5$ & $0.8 \pm 0.4$ \\
\hline
\end{tabular}

* Values are mean $\pm \mathrm{SD}$. Abbreviations: LVO, left ventricular output; Qp, pulmonary blood flow; PDA, left-to-right blood flow through the patent ductus arteriosus; $\overline{\mathrm{P}}_{\mathrm{pa}}$, mean pulmonary artery pressure; $\overline{\mathrm{P}}_{\mathrm{fa}}$, mean femoral artery pressure; $\mathrm{P}_{\mathrm{LVED}}$, left ventricular end-diastolic pressure.

$\dagger p<10^{-7}$ vs closed ductus value.

$\ddagger p<3 \times 10^{-3}$ vs closed ductus value.

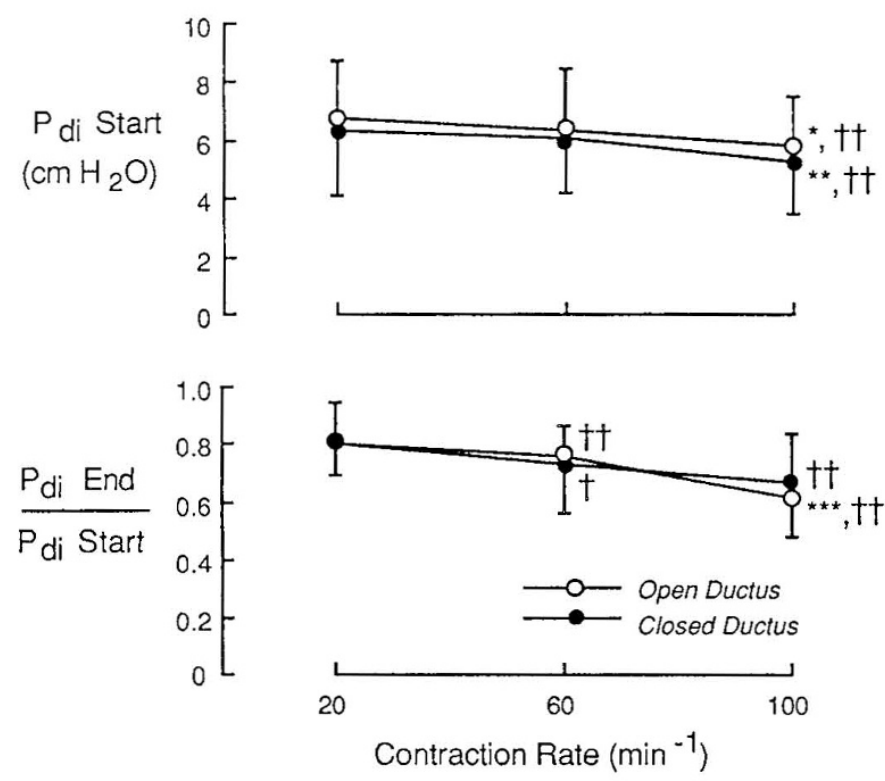

Fig. 3. $P_{\mathrm{di}}$-start and $\mathrm{P}_{\mathrm{di}}$-end/ $/ \mathrm{P}_{\mathrm{di}}$-start when ductus was open and when it was closed. Values did not differ between open and closed ductus states at any contraction rate. Compared with $20 / \mathrm{min}: \dagger p<0.02 ; \dagger \uparrow p<$ 0.005 . Compared with $60 / \mathrm{min}: * p<0.04 ; * * p<0.005 ; * * * p<0.0005$.

whether the ductus was open or closed. This increase in organ blood flow with contraction was observed only in the diaphragm (Table 3). The distribution of total diaphragmatic blood flow to the costal and crural sections of the diaphragm was unchanged whether the diaphragm was at rest or contracting (Table 3).

Increasing rates of diaphragmatic contraction brought no significant changes in arterial or phrenic venous oxygen content
(Table 5). In addition, these variables did not differ at any contraction rate whether the ductus was open or closed (Table $5)$. At contraction rates of $20 / \mathrm{min}$, in both the open and closed ductus states, diaphragmatic oxygen consumption increased 11fold over oxygen consumption at rest (Fig. 4). At contraction rates of $100 / \mathrm{min}$, there was a further 1.8 -fold and 1.1 -fold increase in oxygen consumption with the ductus open and closed, respectively. At contraction rates of $20 / \mathrm{min}$, diaphragmatic oxygen delivery increased 12-fold (open ductus) and 9-fold (closed ductus) over oxygen delivery at rest, and contraction rates of $100 / \mathrm{min}$ brought a further 1.9 -fold and 1.3 -fold increase with open and closed ductus, respectively. Thus, the increase in oxygen consumption with increased rates of contraction was more than adequately met by increased rates of oxygen delivery; as a result, there was no significant change in the oxygen extraction ratio. Lactate efflux also increased with increasing rates of contraction. At no rate of contraction were these variables of oxygen and lactate metabolism affected by open or closed ductal state.

The 11 lambs used to examine the effects of the ductus arteriosus on diaphragm performance (group 2) were studied initially with the ductus open and then with the ductus closed. To confirm that the observed changes were independent of this time course, we compared the 11 lambs in group 2 during their initial sequence of pacing (i.e. when their ductus was open) with the five lambs in group 1 during their initial sequence of pacing (when their ductus was closed-period I) so that both groups were studied at the same age after delivery. Hemodynamic variables in the five group 1 lambs (with a closed ductus) were similar to the values in the 11 group 2 lambs when their ductus was closed. Indices of oxygen metabolism could be obtained in only three animals in group 1; although this invalidates meaningful statistical comparison, the results were of the same order of magnitude as those obtained in the group 2 animals. $P_{\text {di }}$-start and the ratio $\mathrm{P}_{\mathrm{di}}$-end $/ \mathrm{P}_{\mathrm{di}}$-start did not differ significantly between the two groups of animals (Table 6). 
Table 3. Regional blood flows in fetal lambs with open and closed ductus when diaphragm was at rest and at different rates of contraction $(n=11)^{*}$

\begin{tabular}{|c|c|c|c|c|}
\hline & \multicolumn{4}{|c|}{ Flow $\left(\mathrm{mL} \cdot \mathrm{min}^{-1} \cdot 100 \mathrm{~g}^{-1}\right)$} \\
\hline & Rest & $20 / \min$ & $60 / \mathrm{min}$ & $100 / \mathrm{min}$ \\
\hline \multicolumn{5}{|l|}{ Open ductus } \\
\hline$\dot{\mathrm{Q}}_{\mathrm{di}}$ & $4.0 \pm 3.8 \dagger$ & $41.0 \pm 16.8 \ddagger$ & $50.3 \pm 22.9 \div \S$ & $68.0 \pm 34.2 \ddagger \S$ \\
\hline$\dot{Q}_{\text {costai }}(\%)$ & $56 \pm 37$ & $63 \pm 11$ & $64 \pm 10$ & $65 \pm 10$ \\
\hline$\overline{\mathrm{Q}}_{\text {crural }}(10)$ & $\overline{44 \pm 37}$ & $\overline{37 \pm 11}$ & $\overline{36 \pm 10}$ & $\overline{35 \pm 10}$ \\
\hline$\dot{Q}_{\text {scap }}$ & $4.4 \pm 2.4 \dagger$ & $3.9 \pm 1.8 \dagger$ & $3.3 \pm 1.5 \dagger$ & $3.1 \pm 1.7 \dagger \|$ \\
\hline Q & $5.3 \pm 1.7 \dagger$ & $4.9 \pm 2.3 \dagger$ & $4.8 \pm 1.8 \dagger$ & $4.3 \pm 1.8+\pi$ \\
\hline$\dot{Q}_{\text {gut }}$ & $48 \pm 23 \dagger$ & $37 \pm 19 \dagger$ & $36 \pm 19 \dagger$ & $39 \pm 21 \dagger$ \\
\hline$\dot{Q}_{\text {liver }}$ & $31 \pm 23$ & $31 \pm 21$ & $28 \pm 16$ & $27 \pm 11$ \\
\hline$\dot{Q}_{\text {kidncy }}$ & $68 \pm 34 \dagger$ & $73 \pm 33$ & $78 \pm 39$ & $80 \pm 46$ \\
\hline$\dot{Q}_{\text {brain }}$ & $31 \pm 13$ & $29 \pm 9$ & $27 \pm 8$ & $26 \pm 9$ \\
\hline \multicolumn{5}{|l|}{ Closed ductus } \\
\hline$\dot{Q}_{d i}$ & $7.4 \pm 2.4$ & $50.8 \pm 25.3 \ddagger$ & $55.2 \pm 31.1 \neq$ & $72.8 \pm 34.9 \ddagger$ \\
\hline$\dot{Q}_{\text {costal }}(\%)$ & $69 \pm 13$ & $62 \pm 12$ & $62 \pm 13$ & $66 \pm 13$ \\
\hline$\dot{\mathrm{Q}}_{\text {crural }}$ & $\overline{31 \pm 13}$ & $\overline{38 \pm 12}$ & $38 \pm 13$ & $\overline{34 \pm 13}$ \\
\hline$\dot{Q}_{\text {scap }}$ & $5.9 \pm 3.5$ & $6.9 \pm 3.6$ & $6.3 \pm 3.2$ & $5.6 \pm 3.2$ \\
\hline$\dot{Q}_{\text {carc }}$ & $6.7 \pm 2.6$ & $7.0 \pm 2.6$ & $6.4 \pm 3.1$ & $6.5 \pm 3.1$ \\
\hline$\hat{Q}_{\text {gut }}$ & $74 \pm 33$ & $73 \pm 32$ & $68 \pm 36$ & $66 \pm 30$ \\
\hline$\dot{\mathrm{Q}}_{\text {liver }}$ & $35 \pm 22$ & $33 \pm 17$ & $31 \pm 21$ & $32 \pm 18$ \\
\hline$\dot{Q}_{\text {kidney }}$ & $91 \pm 48$ & $92 \pm 51$ & $88 \pm 48$ & $85 \pm 47$ \\
\hline$\dot{Q}_{\text {brain }}$ & $27 \pm 8$ & $30 \pm 8$ & $27 \pm 9$ & $27 \pm 7$ \\
\hline
\end{tabular}

*Values are mean $\pm \mathrm{SD}$. Abbreviations: $\dot{\mathrm{Q}}_{\mathrm{di}}$, total diaphragm blood flow; $\frac{\dot{\mathrm{Q}}_{\text {costal }}}{\dot{\mathrm{Q}}_{\text {crural }}}$, percentage of total diaphragmatic blood flow to the costal/crural muscle; $\dot{\mathrm{Q}}_{\mathrm{scap}}, \dot{\mathrm{Q}}_{\mathrm{carc}}, \dot{\mathrm{Q}}_{\mathrm{guu}}, \dot{\mathrm{Q}}_{\mathrm{liver}}, \dot{\mathrm{Q}}_{\mathrm{kidncy}}$, and $\dot{\mathrm{Q}}_{\text {brain, }}$, arterial blood flow to the scapula muscle, carcass, gastrointestinal tract, liver, kidneys, and brain, respectively.

$\dagger p<0.02$ vs closed ductus value.

$\ddagger p<0.001$ is value at rest.

$\$ p<0.05$ w value at $20 / \mathrm{min}$.

$\| p<0.06$ vs value at rest.

I $p<0.01$ vs value at rest.

Table 4. Diaphragmatic vascular resistance $\left[\mathrm{mm} \mathrm{Hg} \cdot \mathrm{mL}^{-1} \cdot \mathrm{min} \cdot 100 \mathrm{~g}\left(\mathrm{kPa} \cdot \mathrm{mL}^{-1} \cdot \mathrm{min} \cdot 100 \mathrm{~g}\right)\right]$ in lambs with open or closed ductus at different contraction rates $(n=5)^{*}$

\begin{tabular}{|c|c|c|c|c|}
\hline & Rest & $20 / \min$ & $60 / \mathrm{min}$ & $100 / \mathrm{min}$ \\
\hline Open ductus & $\begin{array}{c}11.9 \pm 7.8 \\
(1.58 \pm 1.03)\end{array}$ & $\begin{array}{c}1.1 \pm 0.5 \dagger \\
(0.15 \pm 0.07)\end{array}$ & $\begin{array}{c}0.85 \pm 0.5 \dagger \\
(0.11 \pm 0.07)\end{array}$ & $\begin{array}{r}0.8 \pm 0.6+\ddagger \\
(0.10 \pm 0.08)\end{array}$ \\
\hline Closed ductus & $\begin{array}{c}6.8 \pm 2.3 \\
(0.90 \pm 0.31)\end{array}$ & $\begin{aligned} 1.1 & \pm 0.7 \dagger \\
(0.15 & \pm 0.09)\end{aligned}$ & $\begin{array}{r}1.1 \pm 0.75 \dagger \\
(0.15 \pm 0.10)\end{array}$ & $\begin{array}{r}0.8 \pm 0.5+5 \\
(0.10 \pm 0.07)\end{array}$ \\
\hline
\end{tabular}

* Values are mean $\pm \mathrm{SD}$.

$\dagger p<3 \times 10^{-3} v s$ value at rest.

$\ddagger p<0.02$ vs value at $20 / \mathrm{min}$.

Table 5. Metabolism in diaphragm in lambs with open or closed ductus at different contraction rates $(n=5)^{*}$

\begin{tabular}{lcccc}
\hline & Rest & $20 / \mathrm{min}$ & $60 / \mathrm{min}$ & $100 / \mathrm{min}$ \\
\hline Open ductus & & & & \\
$\mathrm{C}_{\mathrm{a}}\left(\mathrm{mL} \mathrm{O}_{2} / 100 \mathrm{~mL}\right)$ & $16.6 \pm 4.7$ & $16.4 \pm 4.4$ & $17.6 \pm 4.0$ & $17.4 \pm 3.9$ \\
$\mathrm{C}_{\mathrm{i}-\mathrm{v}}\left(\mathrm{mL} \mathrm{O}_{2} / 100 \mathrm{~mL}\right)$ & $8.5 \pm 4.1$ & $8.1 \pm 3.8$ & $8.2 \pm 2.1$ & $8.1 \pm 2.3$ \\
$\mathrm{O}_{2} \mathrm{Sat}_{\mathrm{pv}}(\%)$ & $45.6 \pm 17.9$ & $48.8 \pm 17.3$ & $49.7 \pm 4.6$ & $50.5 \pm 7.5$ \\
{$[\mathrm{lac}]_{\mathrm{vad}}(\mathrm{mmol} / \mathrm{L})$} & $0.54 \pm 0.32$ & $0.49 \pm 0.57$ & $1.04 \pm 0.88$ & $1.00 \pm 0.91$ \\
$\mathrm{Closed} \mathrm{ductus}_{\mathrm{C}_{\mathrm{a}}\left(\mathrm{mL} \mathrm{O}_{2} / 100 \mathrm{~mL}\right)}$ & $15.0 \pm 4.1$ & $15.7 \pm 4.6$ & $18.0 \pm 2.7$ & $15.4 \pm 4.6$ \\
$\mathrm{C}_{\mathrm{a}-\mathrm{v}}\left(\mathrm{mL} \mathrm{O}_{2} / 100 \mathrm{~mL}\right)$ & $5.2 \pm 1.7$ & $6.3 \pm 3.9$ & $6.1 \pm 3.0$ & $5.7 \pm 3.6$ \\
$\mathrm{O}_{2} \mathrm{Sat}_{\mathrm{pv}}(\%)$ & $60.8 \pm 20.5$ & $55.1 \pm 27.1$ & $64.0 \pm 12.3$ & $57.7 \pm 27.2$ \\
{$[\mathrm{lac}]_{\mathrm{va}}(\mathrm{mmol} / \mathrm{L})$} & $0.33 \pm 0.76$ & $0.38 \pm 0.68$ & $0.83 \pm 0.31$ & $1.08 \pm 0.71$ \\
\hline
\end{tabular}

* Values are mean \pm SD. Abbreviations: $C_{a}$, diaphragmatic arterial oxygen content; $C_{a-v}$, diaphragmatic arteriovenous oxygen content difference; $\mathrm{O}_{2} \mathrm{Sat}_{\mathrm{pv}}$, oxygen saturation in phrenic vein; [lac $]_{v-1}$, diaphragmatic arteriovenous lactate concentration difference.

\section{DISCUSSION}

Our purpose was to study the perinatal effects of ductus patency on diaphragmatic function and blood flow. We cannot speculate on the effects of very prolonged ductus patency on diaphragmatic function. Furthermore, our findings do not reflect on the effects of ductus patency on the diaphragm's maximal work capacity or endurance; to answer these questions, a different experimental model would be required. Our aim was to create a model in which diaphragmatic contractile dysfunction could be 

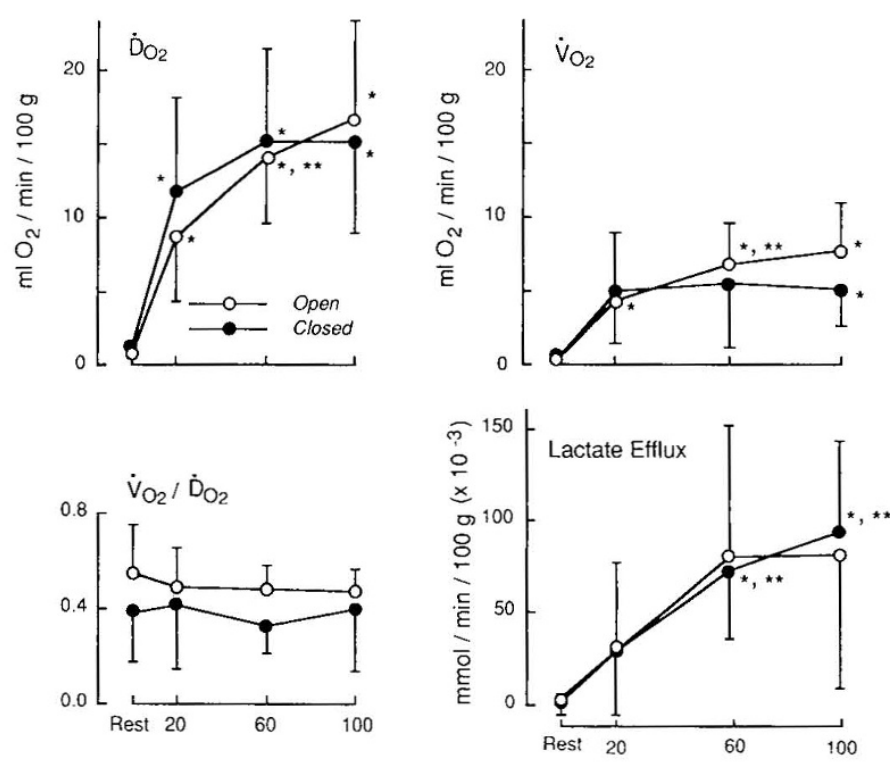

Contraction Rate $\left(\min ^{-1}\right)$

Fig. 4. Indices of diaphragmatic oxygen metabolism at rest and at various contraction rates. There were no differences between open and closed ductus states. $\dot{\mathrm{D}} \mathrm{O}_{2}$, oxygen delivery; $\dot{\mathrm{V}}_{2}$, oxygen consumption; $\dot{\mathrm{V}}_{2} / \dot{\mathrm{DO}}_{2}=$ oxygen extraction ratio. ${ }^{*} p<0.03$ vs rest; ${ }^{* *} p<0.05$ vs $20 /$ $\mathrm{min}$. The increase in lactate efflux with increasing rates of contraction did not achieve statistical significance when the ductus was open because of the large variability observed. In each individual animal, however, net lactate efflux increased with increasing rates of contraction.

reproducibly demonstrated, and then to see whether a left-toright ductus shunt would significantly decrease diaphragmatic function under the same conditions.

We used an artificial preparation to study the effects of the ductus shunt on the diaphragm itself, without the confounding effects of the ductus on pulmonary mechanics, ventilatory drive, or chest wall stability. Although diaphragmatic pacing is not identical to spontaneous breathing, it is useful for controlling rates and patterns of breathing. The chest was open to eliminate the effects of lung expansion on diaphragmatic configuration and to minimize the diaphragm's interaction with the chest wall. We measured $\mathrm{P}_{\mathrm{di}}$ using a balloon catheter placed between the abdominal wall and the restrictive abdominal bandage. Although diaphragmatic contractile force is usually assessed by the difference between $\mathrm{P}_{\mathrm{ga}}$ and esophageal (pleural) pressure, this measure is also an indirect index of diaphragmatic contractility and is affected by diaphragm position and abdominal compliance, as well as by diaphragmatic contractile force. Furthermore, $\mathrm{P}_{\mathrm{ga}}$ only reflects local pressure under one area of the diaphragm, inasmuch as abdominal pressure has been shown to be nonuniform (18). Thus, transdiaphragmatic pressure, as estimated by the difference between $\mathrm{P}_{\mathrm{ga}}$ and esophageal pressure, may frequently contain substantial errors (18). The purpose of our study was to compare diaphragmatic force during different states of ductus patency; therefore, the most important attribute of any indirect measure of diaphragmatic performance was its reproducibility. Table 1 shows that our measure of $\mathrm{P}_{\mathrm{di}}$ detected similar changes in transdiaphragmatic pressure as did $\mathrm{P}_{\text {ga }}$. Figure 2 shows that our measure of contractile force was reproducible. The abdomen was bandaged to increase the diaphragmatic work load by increasing the abdominal pressure against which the diaphragm contracted. This increased abdominal pressure could affect both diaphragmatic venous pressure and blood flow (8). These considerations would be unlikely to affect our results because, once placed, the tension in the bandage was not changed. Thus, comparisons at different contraction rates and different states of ductus patency were made under similar external restrictions. Furthermore, Buchler et al. (19) have shown that although high abdominal pressures do indeed affect diaphragmatic blood flow during sustained tetanic contractions (duty cycle $=1$ ), the diaphragmatic blood flow is unaffected during intermittent diaphragmatic contractions (duty cycle $<1$ ). The above considerations apply equally to the studies performed with the ductus open and those with the ductus closed. Because our interest lay in comparing the effects of an open ductus with those of a closed one, we believe that our results are qualitatively applicable.

We found that as diaphragmatic contraction rates increased, so did oxygen consumption and lactate production by the diaphragm. Despite this increased metabolic rate, there was a decrease both in diaphragmatic contractile force $\left(\mathrm{P}_{\mathrm{d}}\right.$-start $)$ and in the diaphragm's ability to sustain this contractile force $\left(\mathrm{P}_{\mathrm{di}}\right.$-end/ $\mathrm{P}_{\mathrm{di}}$-start) with progressive increases in contraction frequency. It is interesting that diaphragmatic contractile dysfunction with increasing rates of contraction was already apparent at the beginning of each train of pacing $\left(\mathrm{P}_{\mathrm{di}}\right.$-start). This is compatible with the suggestion of Buchler et al. (7) that energy expenditure associated with activation may be more important than that associated with shortening.

We also found that patency of the ductus arteriosus, which was associated with a decreased perfusion pressure, did not cause greater reductions in diaphragmatic contractile force or ability to sustain contractile force. In the presence of an open ductus, blood flow to the diaphragm, when the diaphragm was not contracting, was reduced by nearly $50 \%$. However, once the diaphragm started to contract, diaphragmatic blood flow increased markedly, so that there was no significant difference in flows whether the ductus was open or closed.

Would greater left-to-right shunts or greater work loads have affected our results differently? With the ductus open, left-toright shunts ranged from 37 to $78 \%$ of left ventricular output. Using Spearman's rank correlation test, we found no correlation between the magnitude of the ductus left-to-right shunt and either the blood flow to the contracting diaphragm or the indices of diaphragmatic function $\left(\mathrm{P}_{\mathrm{di}}\right.$-start, $\mathrm{P}_{\mathrm{di}}$-end $/ \mathrm{P}_{\mathrm{di}}$-start $)$. Although our experiment was not designed to demonstrate maximal achievable diaphragmatic blood flows, the fact that diaphragmatic vascular resistance approached a nadir at the higher rates of contraction (Table 4) leads one to believe that little further increase in blood flow would be expected without a change in perfusion pressure. In addition, applying the formula of Reid and Johnson $(4,20)$, the blood flow observed at contraction rates of $100 / \mathrm{min}$ should have been the maximal possible blood flow to the diaphragm at that perfusion pressure. Thus, our experimental model may have achieved near-maximal diaphragmatic blood flow. If this were the case, then our results would indicate

Table 6. Comparison of $P_{d i}$-start and $P_{d i}$-end/P $P_{d i}$-start in lambs in which ductus was either closed initially (group 1) or open initially (group 2)*

\begin{tabular}{|c|c|c|c|c|c|c|}
\hline & \multicolumn{3}{|c|}{$\mathrm{P}_{\mathrm{di}}$-start $\left(\mathrm{cm} \mathrm{H} \mathrm{H}_{2} \mathrm{O}\right)$} & \multicolumn{3}{|c|}{$\mathrm{P}_{\mathrm{di}}$-end $/ \mathrm{P}_{\mathrm{di}}$-start } \\
\hline & $20 / \mathrm{min}$ & $60 / \mathrm{min}$ & $100 / \mathrm{min}$ & $20 / \mathrm{min}$ & $60 / \min$ & $100 / \mathrm{min}$ \\
\hline Open ductus ( $n=11$ ) & $6.8 \pm 1.9$ & $6.3 \pm 2.1$ & $5.8 \pm 1.7$ & $0.80 \pm 0.15$ & $0.76 \pm 0.11$ & $0.62 \pm 0.14$ \\
\hline Closed ductus $(n=5)$ & $4.9 \pm 0.9$ & $4.8 \pm 0.8$ & $4.4 \pm 0.5$ & $0.82 \pm 0.05$ & $0.73 \pm 0.10$ & $0.57 \pm 0.15$ \\
\hline
\end{tabular}

$*$ Values are mean $\pm \mathrm{SD}$. There were no significant differences between groups at any contraction rate. 
that even with a large left-to-right shunt, maximal diaphragmatic blood flow does not differ from that seen when the ductus is closed.

Therefore, the contracting diaphragm in this experimental model appears to be protected from ductus "steal." It is of interest to speculate on the source of this compensatory blood flow. The observed trend for scapular muscle and carcass blood flows to decrease with increasing rates of diaphragmatic contraction when the ductus was open suggests that there might be redistribution of blood from the carcass to the diaphragm under these conditions. Our study, however, cannot provide conclusive evidence for this. Although the blood flow to the contracting diaphragm (per $100 \mathrm{~g}$ tissue) was considerable, the absolute amount of blood flow to the diaphragm was low compared with the amount of blood flow to the carcass. Thus, a small percentage decrease in carcass blood flow, not sufficient to achieve statistical significance in our study, would suffice to provide the source of additional blood flow to the contracting diaphragm. Previous observations have also suggested that the working diaphragm was a protected organ in adverse hemodynamic conditions. Magder et al. (21) found that with severe inspiratory elastic loading, blood flow increased mainly to the diaphragm and external intercostal muscles. When severe hypotension was then induced by cardiac tamponade, diaphragmatic blood flow was maintained at its increased level, whereas blood flow to other vital organs, including brain and heart, decreased.

Seaberg et al. (22) studied the effects of a patent ductus arteriosus on exercising skeletal muscle blood flow in piglets. They found that treadmill exercise increased skeletal muscle blood flow equally whether the ductus was open or closed. In their study, however, ductus left-to-right shunting decreased during exercise, mainly due to decreased systemic vascular resistance and increased pulmonary vascular resistance. In our study, ductus shunting did not change with increasing rates of contraction; we essentially activated only one muscle, and no changes in systemic or pulmonary vascular resistance were noted.

Several investigators have suggested that control of diaphragmatic vascular resistance is related to the $\mathrm{PO}_{2}$ in the phrenic vein $(4,23)$. However, the changes in diaphragmatic vascular resistance that occurred in our study (Table 4) were independent of phrenic venous oxygen tension (Table 5). Furthermore, most of our animals had phrenic venous oxygen saturations greater than the levels that had previously been shown to affect resistance (4, 23). Thus, in the newborn lamb, diaphragmatic vascular resistance also must be affected by mechanisms that are independent of phrenic venous oxygen tensions.

With increased rates of contraction, with both open and closed ductus, crural and costal diaphragmatic blood flows increased similarly (Table 3 ). At each rate of contraction, however, crural blood flow (per g tissue) exceeded costal blood flow (data not shown). This is consistent with results obtained by Soust et al. (24) in sheep 8 to $10 \mathrm{wk}$ of age during quiet breathing. The crural and costal portions of the diaphragm have different mechanical action (14), and under conditions of inspiratory resistive loading, the crural EMG activity undergoes greater augmentation than does the costal activity (25). Although the specific blood flow to the crural muscle is greater, the costal diaphragmatic muscle receives a greater proportion of total diaphragmatic blood flow due to its larger weight (Table 3). Our results differ from those of Manohar (26), who found that resting ponies have similar crural and costal blood flows, but that with exercise, costal blood flows were considerably greater than crural blood flows. This may reflect species differences.

Consistent with the findings reported in our study, Nichols et al. (17) found that with increasing rates of contraction, diaphragmatic blood flow, oxygen consumption, and oxygen delivery all increased in the newborn lamb. However, their results differ from ours in that they found that oxygen extraction increased with diaphragmatic contraction, whereas we found that it did not change. Nichols et al. (17) also observed increased lactate efflux with increased rates of diaphragmatic contraction and concluded that this was evidence that maximal oxygen delivery had been superceded. In our study, the increase in diaphragmatic oxygen consumption with increased rates of contraction was more than offset by the increased rate of oxygen delivery. However, even in our own study, despite the unchanged oxygen extraction ratio, net diaphragmatic lactate efflux was noted to increase with increasing rates of contraction. The diaphragm is capable of metabolizing lactate (27), and net lactate efflux reflects the balance between rates of uptake and production. Conclusions about either pathway alone cannot be made from a single measurement of efflux. Rochester and Briscoe (28) estimated phrenic venous $\mathrm{PO}_{2}$ to be $15-20$ torr $(2.0-2.7 \mathrm{kPa})$ before significant lactate production by the canine diaphragm was observed. More recently, Reid and Johnson (4) estimated critical phrenic venous $\mathrm{PO}_{2}$ to be less than 12 torr $(1.6 \mathrm{kPa})$ before aerobic work capacity of the diaphragm was diminished. Most of the animals in our study and that of Nichols et al. (17) had phrenic venous $\mathrm{PO}_{2}$ values above these levels. It is possible that the neonatal diaphragm is more susceptible to hypoxia, but recent work in newborn piglets and baboons actually suggests, based on both functional and histochemical evidence, that the newborn diaphragm is better able to tolerate hypoxia than is the diaphragm of the older animal $(29,30)$. On the other hand, lactic acid, moreover, is not necessarily an indicator of anaerobic metabolism (31). The diaphragm is composed of various fiber types, some of which have low oxidative capacity (32). In studies such as ours and that of Nichols et al. (17), in which the diaphragm is paced at supramaximal voltage, all fibers are activated. Net lactate efflux, therefore, may reflect additional fiber recruitment rather than lack of oxygen.

In summary, we have shown that patency of the ductus arteriosus does not adversely affect diaphragmatic function. Although a patent ductus arteriosus is associated with decreased diaphragmatic blood flow when the diaphragm is at rest, the contracting diaphragm is able to increase its blood flow to levels equivalent to those attained when the ductus is closed. Our results have a clinical application in that premature infants frequently suffer from respiratory distress in the first few days of life. They also frequently have a patent ductus arteriosus. Insofar as our model applies to human physiology, it appears unlikely that the patent ductus would contribute to the respiratory distress in these infants by adversely affecting blood flow to the respiratory muscles.

Acknowledgments. The authors thank Dr. Michael A. Heymann for his help in creating the surgical model used in this study and Paul Sagan for his skillful editorial assistance. We thank Carl McWatters and Bruce Payne for their invaluable help with the analysis of the microsphere studies and Dr. Daniel Murai (University of Texas, San Antonio) for designing the EMG electrode and providing us with the equipment to make our own. We also thank Drs. Julio Pérez Fontán (Yale University), Greg Heldt (University of California, San Diego), and John Watchko (University of Pittsburgh) for very helpful suggestions about the experimental model.

\section{REFERENCES}

1. Roussos CS, Macklem PT 1977 Diaphragmatic fatigue in man. J Appl Physiol 43:189-197

2. Rochester DF, Bettini G 1976 Diaphragmatic blood flow and energy expenditure in the dog. J Clin Invest 57:661-672

3. Robertson CH, Foster GH, Johnson Jr RL 1977 The relationship of respiratory failure to the oxygen consumption of, lactate production by, and distribution of blood flow among respiratory muscles during increased respiratory resistance. J Clin Invest 59:31-42

4. Reid MB, Johnson Jr RL 1983 Efficiency, maximal blood flow, and aerobic work capacity of canine diaphragm. J Appl Physiol 54:763-772

5. Robertson CH, Eschenbacher WL, Johnson Jr RL 1977 Respiratory muscle blood flow distribution during expiratory resistance. J Clin Invest 60:473480

6. Bark H, Supinski GS, Lamanna JC, Kelsen SG 1987 Relationship of changes in diaphragmatic muscle blood flow to muscle contractile activity. $\mathrm{J}$ Appl Physiol 62:291-299 
7. Buchler B, Magder S, Roussos C 1985 Effects of contraction frequency and duty cycle on diaphragmatic blood flow. J Appl Physiol 58:265-273

8. Bellemare F. Wight D, Lavigne CM. Grassino A 1983 Effects of tension and timing of contraction on the blood flow of the diaphragm. J Appl Physiol 54:1597-1606

9. Aubier M. Trippenbach T, Roussos C 1981 Respiratory muscle fatigue during cardiogenic shock. J Appl Physiol 51:499-508

10. Scharf SM, Bark H 1984 Function of canine diaphragm with hypovolemic shock and $\beta$-adrenergic blockade. J Appl Physiol 56:648-655

11. Barclay JK 1986 A delivery-independent blood flow effect on skeletal muscle fatigue. J Appl Physiol 61:1084-1090

12. Alpan G, Mauray F, Clyman RI 1989 Effect of patent ductus arteriosus on water accumulation and protein permeability in the lungs of mechanically ventilated premature lambs. Pediatr Res 26:570-575

13. Clyman RI, Mauray F, Heymann MA, Roman C 1987 Cardiovascular effects of a patent ductus arteriosus in preterm lambs with respiratory distress. $J$ Pediatr 111:579-587

14. De Troyer A, Sampson M, Sigrist S, Macklem PT 1981 The diaphragm: two muscles. Science 212:237-238

15. Smith J, Bellemare F 1987 Effect of lung volume on in vivo contraction characteristics of human diaphragm. J Appl Physiol 62:1893-1900

16. Austin RE, Hauck WW, Aldea GS, Flynn AE, Coggins DL, Hoffman JIE 1989 Quantitating error in blood flow measurements with radioactive microspheres. Am J Physiol 257:H280-H288

17. Nichols DG, Howell S, Massik J, Koehler RC, Gleason CA, Buck JR, Fitzgerald RS, Traystman RJ, Robotham JL 1989 Relationship of diaphragmatic contractility to diaphragmatic blood flow in newborn lambs. J Appl Physiol $66: 120-127$

18. Decramer M. De Troyer A, Kelly S, Zocchi L, Macklem PT 1984 Regional differences in abdominal pressure swings in dogs. $\mathbf{J}$ Appl Physiol 57:16821687

19. Buchler B, Magder S, Latsardis H, Jammes J, Roussos C 1985 Effects of pleural pressure and abdominal pressure on diaphragmatic blood flow. J App Physiol 58:691-697
20. Roussos CS 1985 Function and fatigue of respiratory muscles. Chest 88 (suppl): $124 \mathrm{~S}-132 \mathrm{~S}$

21. Magder S, Lockhat D, Luo BJ, Roussos C 1985 Respiratory muscle and organ blood flow with inspiratory elastic loading and shock. $\mathrm{J}$ Appl Physiol 58:1148-1156

22. Seaberg D, Lorenz E, Lund G, Rysary J, Pierpont ME, Zhang S-L, Einsig S 1987 Exercise reduces persistent ductus arteriosus shunting in piglets. Cardiovasc Res 21:847-855

23. Bark H, Supinski GS, Bundy R, Kelsen SG 1988 Effect of hypoxia on diaphragm blood flow, oxygen uptake and contractility. Am Rev Respir Dis 138:1535-154

24. Soust M, Walker AM, Wilson FE, Berger PJ 1987 Origins and regional distribution of blood flow to the respiratory muscles in conscious sheep. Respir Physiol 67:283-294

25. Watchko JF, Mayock DE, Standaert TA, Woodrum DE 1987 Effect of inspiratory resistive loading on costal and crural diaphragm electromyograms in piglets. Pediatr Res 21:25-28

26. Manohar M 1988 Costal vs. crural diaphragmatic blood flow during submaximal and near-maximal exercise in ponies. J Appl Physiol 65:1514-1519

27. Manohar M, Goetz TE, Holste LC, Nganwa D 1988 Diaphragmatic $\mathrm{O}_{2}$ and lactate extraction during submaximal and maximal exertion in ponies. J Appl Physiol 64:1203-1209

28. Rochester DF, Briscoe AM 1979 Metabolism of the working diaphragm. Am Rev Respir Dis 119(suppl): 105-106

29. Watchko JF, LaFramboise WA, Standaert TA, Woodrum DE 1986 Diaphrag matic function during hypoxemia: neonatal and developmental aspects. J matic function during hypox

30. Maxwell LC, McCarter RJM, Kuehl TJ, Robotham JL 1983 Development of histochemical and functional properties of baboon respiratory muscles. J Appl Physiol 54:551-561

31. Brooks GA 1986 Lactate production under fully aerobic conditions: the lactate shuttle during rest and exercise. Fed Proc 45:2924-2929

32. Sieck GC 1988 Diaphragm muscle: structural and functional organization. Clin Chest Med 9:195-210 